Бондарева Л.Л. - доктор с.-х. наук, зав. лаб. селекции и семеноводства капустных культур Носова С.М. - С.н.с. отдела координации НИР

ФГБНУ «Всероссийский научно-исследовательский институт селекции и семеноводства овощных культур» (ФГБНУ ВНИИССОК)

143080, Россия, Московская обл., Одинцовский р-н, п. ВНИИССОК, ул. Селекционная, д.14

E-mail: lyuda_bondareva@mail.ru

В статье показаны основные результаты по селекции капустных культур в России, представлено обоснование как классических, так и новых биотехнологических методов в селекции при создании новых гибридов капусты, отвечаючих современным требованиям потребительского рынка. Представлена краткая информачия о работе Международной научно-практической конференции «Состояние и перспективы селекции и семеноводства капустных культур».

Ключевые слова: капустные культуры, гибрид, межвидовая гибридизация, удвоенные гаплоиды, устойчивость к болезням.

$13-14$ сентября 2016 года в РГАУ-МСХА им. К.А. научно-практическая конференция «Состояние и перспективы селекции и семеноводства капустных культур». Капуста белокочанная в нашей стране является одной из главных овощных культур. По оценкам специалистов, в России более 50 тыс. га занимают товарные посевы капусты белокочанной, а общая площадь - более 120 тыс. га. Ценный биохимический состав, высокая урожайность в различных агроклиматических зонах, пригодность к длительному хранению, переработке и квашению сделали эту культуру народной.

Традиционно работающая на базе ВНИИССОК научнометодическая комиссия по селекции и семеноводству капустных культур (председатель комиссии - доктор с.-х. наук Бондарева Л.Л.) провела свое очередное заседание на базе РГАУ-МСХА и на Селекционной станции им. Н.Н. Тимофееева, где в последние годы на современном уровне проводятся исследования по разработке наукоемких технологий создания исходного материала по актуальным направлениям селекции, а также практической селекции капустных культур. Программа Конференции включала: пленарное заседание, посещение демонстрационного участка капусты белокочанной отечественных и иностранных селекционных фирм в Дмитровском районе Московской области (ГК «Дмитровские овощи»), а также демонстрационное поле селекционера кандидата с.-х. наук Г.Ф. Монахоса.

Главной целью данной конференции являлось создание информационного поля для объединения усилий по скорейшему внедрению в отечественную селекционную практику капустных культур современных и инновационных методов селекции.

Открывая конференцию, генеральный директор Селекционной станции им. Н.Н. Тимофеева Григорий Федорович Монахос отметил, что ожидается конструктивная работа, т.к. на совещании присутствует кворум ученых, селекционеров, специалистов ФГБУ «Госкомиссия РФ по испытанию и охране селекционных достижений», РГАУМСХА, ФГБНУ ВИР, ВНИИССОК, ВНИИ риса, частных селекционно-семеноводческих и коммерческих фирм РФ и ближнего зарубежья: «Гавриш», «Поиск», «СеДек», а также аспиранты, студенты, представители прессы и 
телевидения. На конференцию были приглашены с докладами ученые-селекционеры из ВНИИ масличных культур, ВНИИ кормов, работающие с другими видами Brassica L.

В приветственном слове к участникам конференции ректор РГАУ-МСХА им. К.А. Тимирязева академик РАН В.М. Лукомец сказал, что Тимирязевская сельскохозяйственная академия - родоначальник многих инновационных направлений в мировой аграрной науке. Созданная здесь профессором А.В. Крючковым научная школа по селекции капусты белокочанной позволила создать конкурентоспособные по отдельным показателям гибриды $F_{1}$ капустных культур, при этом закрыта вся линейка гибридов по

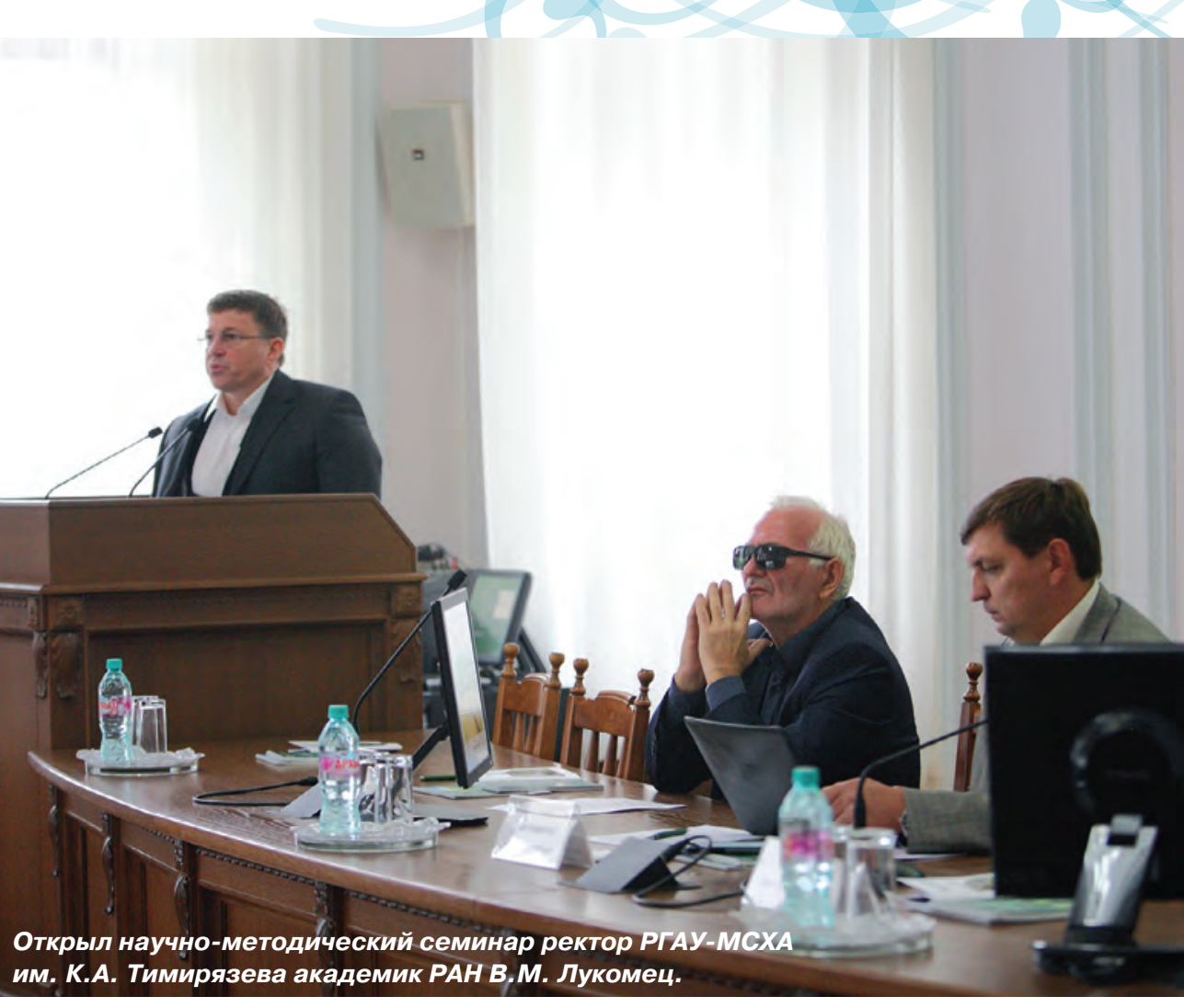
скороспелости. Гибриды капусты селекционной станции им. Н.Н. Тимофеева востребованы в производстве, а коллектив авторов за разработку и внедрение нового направления - создание высокотехнологичных гибридов $F_{1}$ капустных культур удостоен премии Правительства РФ в области науки и техники за 2015 год. Далее он отметил, что российским селекционерам предстоит решить большую проблему импортозамещения, перехода в производстве только на отечественные гибриды. «Надеюсь, сегодняшняя дискуссия, знакомство с различными аспектами исследований в академии, с нашими опытными полями даст дополнительный стимул к развитию сотрудничества наших ученых в области селекции капустных культур», - завершил свое выступление В.М. Лукомец.

Затем слово было представлено председателю Госкомиссии РФ по испытанию и охране селекционных достижений Виталию Сергеевичу Волощенко. Он отметил, что поданная в свое время Н.И. Вавиловым идея о создании эколого-географической селекционной и сортоиспытательной сети обретает новое развитие в связи с задачами создания качественно новой селекционной продукции. Открывающимся перерабатывающим предприятиям нужны гибриды с конкретными показателями качества. В последние годы важнейшим критерием включения в Госреестр селекционных достижений РФ новых гибридов становится устойчивость к болезням.

На 2016 год в Госреестр РФ включены 406 сортов и гибридов капусты белокочанной, в том числе отечественных - 196 и иностранных - 210. Идет борьба за сортимент отрасли. Обстановка сложилась тревожная: отечественное овощеводство на $80 \%$ зависит от поставок семян импортных $\mathrm{F}_{1}$ гибридов.

В настоящее время в связи с выходом Указа Президента РФ от 21.07.2016 №305 «О мерах по реализации государственной научно-технической политики в интересах развития сельского хозяйства» разрабатывается Федеральная научно-техническую программа развития сельского хозяйства на 2017-2025 годы, предусматривающая разработку и реализацию комплекса мер, направленных на создание и внедрение до 2026 года конкурентоспособных отечественных технологий по направлениям отечественного растениеводства, хранения и переработки сельскохозяйственной продукции и др., основанных на новейших достижениях науки. Поэтому совместно с российскими селекционными центрами и производителями семян в ближайшее время предстоит проработать программу по производству оригинальных и элитных семян овощных культур, формированию сортовых ресурсов.

Нашими селекционерами сейчас созданы гибриды капусты белокочанной и других разновидностей для всех регионов страны. ВНИИССОК к тому же сохраняет генофонд исходного материала - уникальных, широкораспространенных старых сортов. Но не решена задача создания форм, устойчивых к злостным заболеваниям - к киле и другим. Особенно острая проблема устойчивости к патогенам на Дальнем Востоке, в Ленинградской области. Для развития приоритетных направлений селекции Госкомиссия РФ планирует скорейшее создание сети фитоучастков в селекцентрах и в условиях, приближенных к производственным (базовые хозяйства), проводить оценку новых гибридов совместно с предприятиями на лежкость, пригодность их к переработке. Надеемся на 


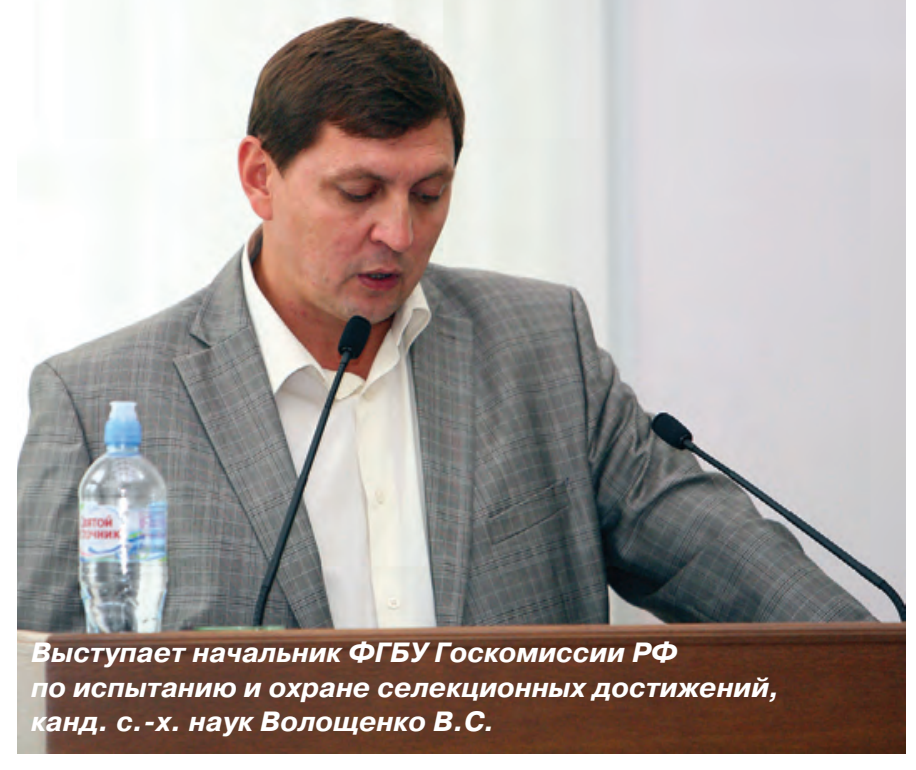

успешное сотрудничество с селекционерами и семеноводами по данным вопросам.

Генеральный директор СС им. Н.Н. Тимофеева, кандидат сельскохозяйственных наук Г.Ф. Монахос в своем выступлении отметил, что российские селекционеры работают в условиях жесткой конкуренции с иностранными фирмами. Ежегодно в Россию ввозится семян на сумму 5 млрд руб., из них 6-7 т семян капусты на сумму 1 млрд руб. Только в хозяйствах Московской области в 2016 году испытывали более 200 иностранных гибридов $F_{1}$. «Семена зарубежных фирм реализуются в РФ по неоправданно высокой цене - 150-200 тыс. руб. за кг, а мы производим на станции в среднем 3 т семян по цене 10-30 тыс. руб., а в целом российские селекционеры могут полностью обеспечить нашу страну семенами капусты белокочанной», - отметил ученый. Созданные к настоящему времени отечественные $F_{1}$ гибриды могут конкурировать с иностранными, но, подчеркнул Г.Ф. Монахос, актуальной задачей является развитие селекционной методологии. «Все селекционеры мира и мы тоже, работаем над проблемой создания генов устойчивости к киле, в т.ч. с использованием межвидовой гибридизации с кормовой репой, редькой и др. Наша задача в настоящее время перевести производство капустных культур на отечественные семена. Это возможно только в том случае, если наши гибриды будут иметь неоспоримые преимущества перед иностранными. В этом плане у нас хорошие перспективы по созданию гибридов с групповой устойчивостью к наиболее злостным заболеваниям: киле, фузариозному увяданию, сосудистому бактериозу, которых не имеют иностранные фирмы. На селекционной станции им. Н.Н.Тимофеева создана к настоящему времени коллекция таких форм. Ведется большая исследовательская работа с использованием отдаленной гибридизации, технологий создания, линий-удвоенных гаплоидов, молекулярного маркирования генов устойчивости. Полученные линии-удвоенные гаплоиды мы оцениваем на комбинационную способность, на лежкость, продуктивность. Наши исследования также показали, что мы можем создать гибриды с генетической устойчивостью к трипсу для южных регионов страны. На станции также разработана схема создания гетерозисных гибридов редиса, дайкона. Все наши $\mathrm{F}_{1}$ гибриды будут защищены цитоплазматической мужской стерильностью и с ними можно выходить на рынок. Этот метод служит беспатентной защитой авторских прав селекционера».

Необходимо также, отметил Г.Ф. Монахос, решить ряд организационных проблем в отрасли. Необходимо, чтобы Госкомиссия РФ по испытанию селекционных достижений в обязательном порядке оценивала на лежкость сорта и гибриды важнейших для здоровья нации овощных культур лука, капусты, свеклы моркови и др. Важнейшая проблема, требующая решения - проблема организации отечественного семеноводства в оптимальных агроклиматических зонах с полным технологическим сопровождением, как это делается во всем мире.

Успешные результаты по разработке новых методических подходов к решению проблемы устойчивости были отражены в докладах молодых ученых: Зубко О.Н., Монахоса С.Г.(РГАУ-МСХА): «Интрогрессия гена устойчивости Rb из B.carinata в B.oleracea»; Монахоса С.Г. (СС им. Н.Н.Тимофеева): «Передача гена устойчивости к киле из B.rapa в B.oleracea посредством отдаленной гибридизации»; Юрченко С.А. (ВНИИ риса): «Создание исходного материала с групповой устойчивостью к болезням».

С обстоятельным докладом выступила заведующая лабораторией селекции и семеноводства капустных культур ВНИИССОК, доктор с.-х. наук Бондарева Л.Л. «Наша лаборатория - старейшее селекционное учреждение по капустным культурам, здесь созданы свои селекционные традиции, создан и сохраняется уникальный и оригинальный исходный материал: сорта Грибовской овощной селекционной станции и ВНИИССОК, используемый многими селекционерами в своей работе». В семидесятые годы здесь был создан первый отечественный гетерозисный гибрид капусты белокочанной. К настоящему времени ассортимент пополнился новыми $\mathrm{F}_{1}$ гибридами капусты белокочанной различных групп спелости, созданными на основе самонесовместимости и с использованием ЦМС. Традиционным направлением нашей селекции является селекция на качество продукции: высокое содержание витаминов, сахаров, БАВ и пониженное содержание клетчатки в продуктовых органах. Содержание сахаров в среднераннем гибриде $\mathrm{F}_{1}$ Зарница, среднепоздних и поздних гибридах $\mathrm{F}_{1}$ Северянка, Мечта, Снежинка и др. составляет 5,5-7,2\%. Они пригодны для хранения, различных видов переработки, имеют отлич- 
ный вкус в свежем виде. Пользуются спросом фермеров и огородников $F_{1}$ гибриды капусты савойской Елена, кольраби Соната, китайской Памяти Поповой и Лиловое чудо, брюссельской Созвездие и др. Проводится большая работа по расширению ассортимента и сортимента различных разновидностей капусты за счет интродукции, селекции, отдаленной гибридизации.

Актуальные направления работы в настоящее время разработка инновационных методов создания $\mathrm{F}_{1}$ гибридов капусты белокочанной и других разновидностей, разработка экспресс-методов оценки исходного материала. Самая сложная задача сейчас - создание генов устойчивости к болезням. Совместно с лабораториями биотехнологии, генетики, иммунитета разработана технология получения удвоенных гаплоидов капустных растений на основе культуры микроспор «іn vitro», которая не только обеспечивает гомозиготность DH-линий, но и расширяет спектр формообразования генетических рекомбинантных форм, в том числе с рецессивными признаками. Новая технология позволяет значительно ускорить селекционный процесс. Получены перспективные гибридные комбинации капусты белокочанной раннего и позднего сроков созревания, брокколи, китайской, кольраби на основе DH-растений, которые получили высокую оценку в селекционном питомнике по комплексу хозяйственно ценных признаков. Способствуют ускорению исследований камеры искусственного климата, которые позволили перевести выращивание в однолетний цикл и полностью исключить переопыление. Практическим результатом данных исследований является создание на основе удвоенных гаплоидов и передача в Государственное сортоиспытание гетерозисного гибрида капусты кольраби Добрыня $\mathrm{F}_{1}$. Лаборатория ведет первичное семеноводство по всем сортам и гибридам под авторским контролем, что позволяет получать семена с высокими сортовыми и посевными качествами и рекомендовать их для решения проблемы импортозамещения.

О результатах эффективного использования биотехнологических методов доложили молодые ученые: Е.А. Заблоцкая (ВНИИССОК) в докладе «Селекция капусты брокколи с использованием линий - удвоенных гаплоидов»; Байдина А.В. (СС им. Н.Н. Тимофеева): «Изучение линий удвоенных гаплоидов капусты белокочанной».

Заведующая отделом овощекартофелеводства ВНИИ риса кандидат с.-х. наук С.В. Королева доложила об исследованиях в институте по селекции капусты белокочанной для южных регионов страны. Она обратила внимание слушателей на специфику региона: он благоприятен для выращивания ранней продукции, и крайне жесткие климатические условия создаются при выращивании среднепоздних гибридов. Поэтому важное направление селекционной работы в отделе - создание адаптивных к биотическим и абиотическим факторам гибридов: скороспелых, устойчивых к фузариозному увяданию, жаростойких, устойчивых к

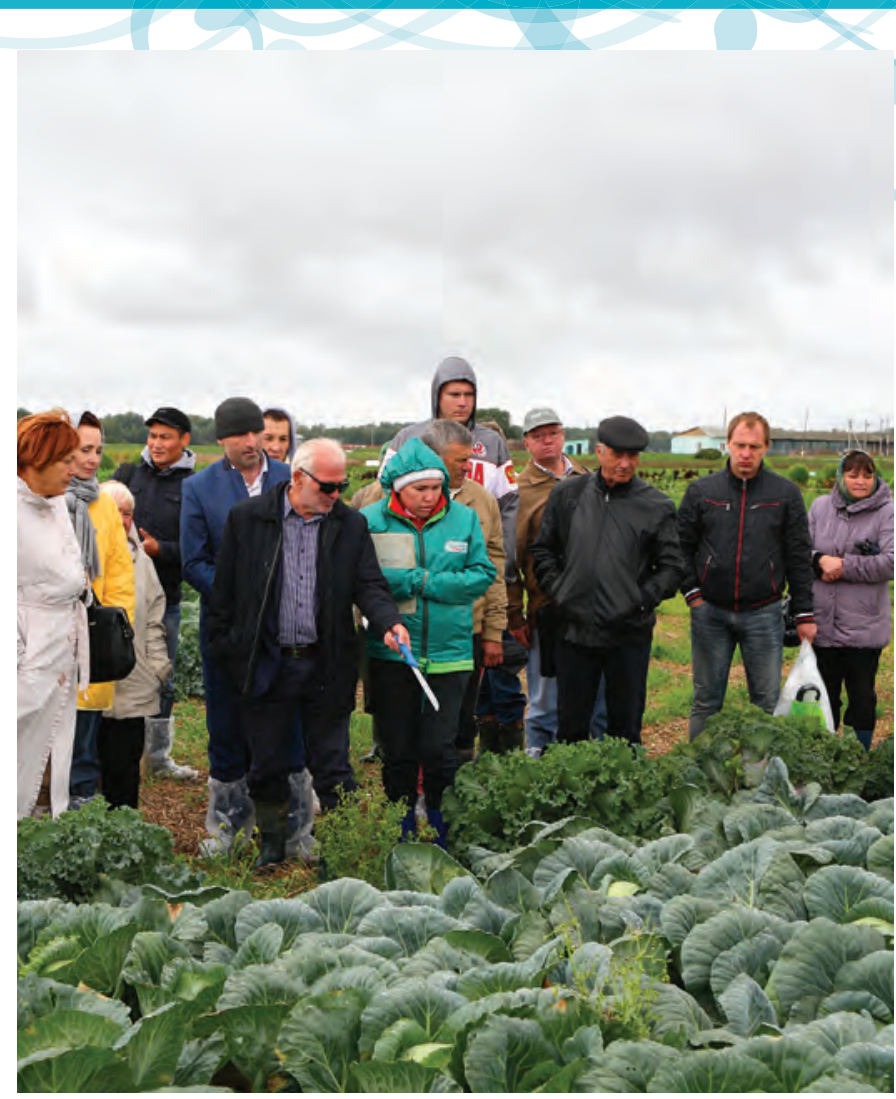

табачному трипсу; позднеспелых, устойчивых к фузариозному увяданию, сосудистому бактериозу, трипсу, с урожайностью 80-90 т/га; а также гибридов с высоким качеством продукции, высокой товарностью, транспортабельных, с лежкостью 4-6 месяцев.

В своем выступлении она подчеркнула, что южные регионы являются поставщиками ранней капусты. В Краснодарском крае укрывная культура занимает более 1000 га. К настоящему времени на основе самонесовместимости в ВНИИ риса создан ряд конкурентоспособных гибридов $F_{1}$ разных сроков созревания и для разных технологий $\mathrm{F}_{1}$ Марьяна, Орбита, Реванш и др. Все гибриды устойчивы к наиболее вредоносному заболеванию - фузариозному увяданию, способны формировать высокий урожай в условиях юга. Так, в Госреестр РФ включен новый ультрараннеспелый гибрид $\mathrm{F}_{1}$ Рица, устойчивый к фузариозу, с урожайностью до 80 т/га, с устойчивостью к растрескиванию 100\%, с высокой товарностью и выровненностью кочанов. Что касается слизистого бактериоза, то получены толерантные линии, но для полной защиты проводятся исследования также по выявлению генисточников расоспецифической устойчивости к этой болезни и объединения в одном генотипе различных видов устойчивости. Исследования сложные, так как требуют большой работы по созданию инфекционных фонов.

В отделе расширены исследования по получению дигаплоидных растений капусты. Это позволило получить новый исходный материал - выровненные линии среднего срока созревания, с урожайностью 110 т/га, и уже подготовлен к передаче раннеспелый гибрид с участием дигаплоидной линии. Большую проблему сейчас представляет табачный трипс, вредоносность которого усилилась из-за сильной 


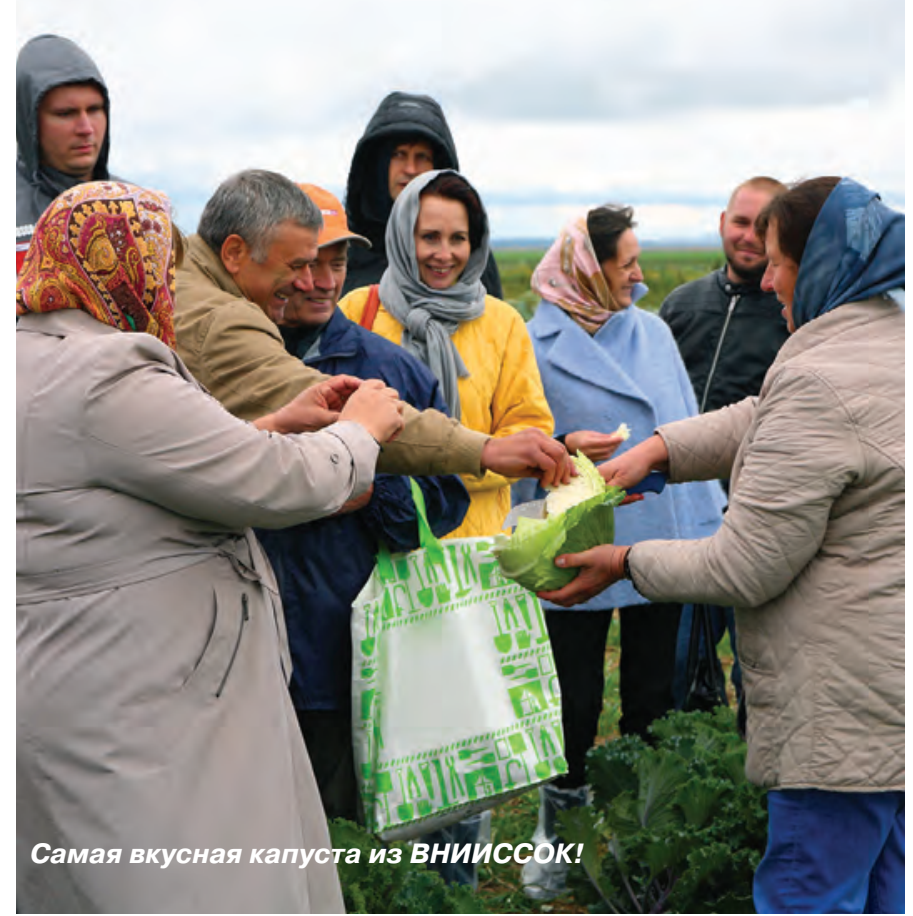

жары, особенно на среднепоздних гибридах. В институте практически решили эту проблему и учеными создан ряд гибридов с устойчивостью к трипсу и к ожогу верхушки листьев.

Ведущий научный сотрудник группы селекции капустных культур ВНИИО, кандидат с.-х. наук Г.А. Костенко доложила о расширении исследований по селекции капусты белокочанной, проводимых совместно с агрофирмой «Поиск». В Госреестр РФ внесены более $20 \mathrm{~F}_{1}$ гибридов агрофирмы для Нечерноземной зоны и ЦчО, различных сроков созревания, рекомендуемых для импортозамещения в РФ. Селекция ведется на универсальное использование - для свежего потребления и квашения. Результаты широкого сортоиспытания новых $F_{1}$ гибридов в различных регионах РФ показывают, что они конкурируют с иностранными аналогами по важнейшим хозяйственно ценным признакам. Так, один из новых гибридов капусты белокочанной Дмитровский $F_{1}$ превышает по урожайности иностранные аналоги, устойчив к фузариозному увяданию, толерантен к сосудистому бактериозу, обладает высокой устойчивостью к трипсу в условиях Ростовской области, имеет кочаны высокого качества и товарности.

С большим вниманием был встречен доклад зав. отделом овощных культур ФИЦ Всероссийского института генетических ресурсов растений им. Н.И. Вавилова, кандидата сельскохозяйственных наук Артемьевой А.М. Она сообщила, что коллекция овощных культур рода Brassica L. и в частности разновидностей вида B. oleracea L. является одной из наиболее важных и многочисленных в коллекции ВИР, составляет 2513 сортообразцов и постоянно пополняется. В рамках концепции комплексного ботанического, эколого-гео- графического, биохимического, иммунологического и молекулярно-генетического изучения разнообразия Brassica L. B ВИР активно развиваются исследования с использованием MAS-технологий и QTL-анализа, которые позволяют создать маркированные коллекции с идентифицированными и картированными локусами, контролирующими хозяйственно ценные признаки в т.ч. у линий - удвоенных гаплоидов. Это облегчает проблему выбора образцов для целевых селекционно-генетических исследований и поддержание самой коллекции. Ведется работа по созданию генетических коллекций рода Brassica. Для вида B.rapa установлены хромосомные блоки, контролирующие морфологические и биохимические признаки, устойчивость к сосудистому бактериозу.

Большое внимание на конференции было уделено элементам и технологиям семеноводства и производства овощной продукции капустных культур.

Доктор биол. наук Джалилов Ф.С. с кафедры защиты растений РГАУ-МСХА им. К.А. Тимирязева в своем докладе «Разработка комплекса мероприятий по защите капусты от сосудистого бактериоза» представил результаты исследований по различным аспектам проблемы. Так, создана обширная коллекция штаммов Хсс, что позволило с использованием инфекционных фонов создать на селекционной станции им. Н.Н. Тимофеева доноры расоспецифической устойчивости к болезни. Разработана высокоэффективная система, обеспечивающая полную защиту ценозов от сосудистого бактериоза, которая включает наличие севооборота, использование гибридов с расоспецифической и стеблевой устойчивостью, предпосевную подготовку семян, дезинфекцию и защиту рассады с помощью набора биопрепаратов и пестицидов.

Кандидат с.-х. наук Мусаев Ф.Б. (ВНИИССОК) представил результаты совместных исследований с АФИ и С.Петербургским ГЭУ по созданию нового способа высокоточной сортировки семян капусты белокочанной и цветной, редиса и салата, основанном на рентгенографическом методе определения качества семян.

Представитель фирмы «Август», кандидат с.-х. наук Бочкарев С.В., в своем сообщении ознакомил участников с ассортиментом фирмы, насчитывающей около 100 препаратов для комплексной защиты сельскохозяйственных растений, в том числе надежную систему защиты капусты от болезней и вредителей на различных стадиях развития. Фирма представила портал технологического сопровождения с предложениями технологий применения и подбором препаратов.

Аспирантом кафедры защиты растений РГАУ-МСХА им. К.А. Тимирязева Орынбаевым А.Т. было сделано сообщение об эффективном способе дезинфекции семян и рассады капусты от болезни «Использование надуксусной кислоты для обеззараживания от сосудистого бактериоза».

Научный сотрудник Дагестанской ОС ФИЦ ВИГРР им. 
Н.И. Вавилова (ВИР) Гаджимустафаева Е.Г. доложила о результатах исследований по подбору сортимента капусты цветной и брокколи для овощеводства в условиях вертикальной зональности (равнина, предгорья, горные районы) Дагестана.

14 сентября участники конференции ознакомились с гибридами капусты отечественной селекции на Демонстрационном поле в д. Бунятино Дмитровского района. Во время проведенной дискуссии специалистами по селекции и семеноводству капусты отмечено, что гибриды отечественной селекции являются конкурентоспособными, а отдельные из них превосходят гибриды иностранной селекции.

В заключение участники конференции пришли к единому мнению о том, что важно поддерживать более тесные связи всех заинтересованных сторон на пути прохождения гибрида от его создания до широкого внедрения в производство, чему и способствуют подобного рода конференции, проведение которых должно быть постоянным.

По результатам работы членами научно-методической комиссии и участниками конференции было принято решение:

- отметить значительные достижения в области фундаментальных исследований по генетике и биотехнологии и в области прикладных исследований по селекции и семеноводству капустных растений на современном этапе и использованию их в практической селекции;

- всемерно активизировать работу по мобилизации и изучению исходного материала для селекции капустных растений с использованием современных методов;

- первоочередной считать работу по созданию гибридов $\mathrm{F}_{1}$ капусты с конкурентными преимуществами в сравнении с зарубежными и отвечающих требованиям потребительского рынка и производства с учетом климатических особенностей регионов РФ;

- усилить исследования в области фундаментальных основ семеноводства и семеноведения капустных растений и технологий производства семян;

- активизировать работу всех сотрудников и, особенно, молодых ученых для участия в конкурсах на получение грантов различного уровня (МСХ РФ, РФФИ, Президентский грант и т.д.);

- провести очередное заседание научно-методической комиссии по капустным культурам в 2019 году на базе ФИЦ ВИГРР им. Н.И. Вавилова (ВИР).

\section{PROMOTION OF COMPETITIVENESS \\ OF NATIONAL DRASSICA BREEDING \\ PROGRAM IS THE MAINEST TASK \\ OF AGRICULTURAL SCIENCE}

Bondareva L.L., Nosova S.M.

Federal State Budgetary Scientific Research Institution

'All-Russian Scientific Research Institute of vegetable

breeding and seed production

143080, Russia, Moscow region,

Odintsovo district, p. VNIISSOK, Selectionnaya st., 14

E-mail: lyuda_bondareva@mail.ru

\section{Summary}

The basic research results of Russian breeding program in Brassica crops were given in the article. Conventional breeding as well as biotechnological methods were used to develop hybrids that meet all requirements of current vegetable market. Brief communication information on international scientific and practical conference "Current State and Trends in Breeding and Seed Production of Brassica crops" was given in the article.

Key words: Brassica crops, hybrid, interspecies hybridization, doubled haploids, resistance to diseases

\section{Лumepamypa}

1.Пивоваров В.Ф. Овощи России / М., 2006. - С.121-122.

2. Современные тенденции развития селекции и семеноводства капустных культур. // Овощи России. - 2013. - №4. C.16-17.

3. Бондарева Л.Л. Селекция и семеноводство капустных культур: основные вехи, направления и результаты. //Селекция и семеноводство овощных культур. - Вып. 44. - 2015. - С.140-145. 